(2) Open Access Full Text Article

\title{
Open mesh and laparoscopic total extraperitoneal inguinal hernia repair under spinal and general anesthesia
}

This article was published in the following Dove Press journal:

Therapeutics and Clinical Risk Management

\author{
Oguzhan Sunamak' \\ Turgut Donmez ${ }^{2}$ \\ Dogan Yildirim ${ }^{3}$ \\ Adnan $\mathrm{Hut}^{3}$ \\ Vuslat Muslu Erdem ${ }^{4}$ \\ Duygu Ayfer Erdem ${ }^{4}$ \\ Ibrahim Halil Ozata ${ }^{2}$ \\ Mikail Cakir ${ }^{3}$ \\ Sinan Uzman ${ }^{5}$
}

'Department of General Surgery, Haydarpasa Numune Training and Research Hospital, Istanbul, Turkey; ${ }^{2}$ Department of General Surgery, Lutfiye Nuri Burat State Hospital, Istanbul, Turkey; ${ }^{3}$ Department of General Surgery, Haseki Training and Research Hospital, Istanbul, Turkey; ${ }^{4}$ Department of Anesthesiology, Lutfiye Nuri Burat State Hospital, Istanbul, Turkey; ${ }^{5}$ Department of Anesthesiology, Haseki Training and Research Hospital, Istanbul, Turkey

Correspondence: Oguzhan Sunamak Department of General Surgery, Haydarpasa Numune Hastanesi,

Tibbiye Caddesi No 40 Uskudar,

34668 Istanbul, Turkey

Tel +905332435I55

Fax +902163460582

Email o.sunamak@yahoo.com.tr
Introduction: Mesh placement is the main standard in repair of inguinal hernia, and laparoscopic repair is the standard of care via spinal, epidural, or combined anesthesia. Here, we compared open and laparoscopic total extraperitoneal (TEP) repairs under general (GA) and spinal anesthesia (SA).

Methods: Inguinal hernia patients $(n=440)$ were analyzed retrospectively. There were four groups: Group 1 was TEP under GA (TEP-GA) (n=111); Group 2 was open mesh repair (OM) under SA ( $n=116)$ (OM-SA); Group 3 was open mesh repair under GA (n=117) (OM-GA); Group four was TEP under SA ( $\mathrm{n}=96)$ (TEP-SA). The age, body mass index, duration of operation, hospital stay, postoperative Visual Analog Scale scores, recurrence, postoperative pain, urinary retention, headache, and patient satisfaction were all recorded.

Results: There was no significant difference in terms of hypotension, vomiting, seroma and scrotal edema, recurrence, and wound infection incidence between the groups. However, the operation duration, hospital stay period, headache, urinary retention, postoperative Visual Analog Scale scores, chronic pain, and patient satisfaction showed significant differences between groups.

Conclusion: Laparoscopic TEP hernia repair is a safe and effective method along with its advantages of shorter hospital stay, less recurrence, less postoperative pain, higher patient satisfaction, and similar postoperative complication rates. SA has the disadvantage of higher incidence of headache and urinary retention compared to GA.

Keywords: herniorrhaphy, laparoscopy, general anesthesia, spinal anesthesia

\section{Introduction}

Inguinal hernia repair is one of the most common operations, but there is no consensus on the optimal operation technique. Recurrence, wound infection, scrotal edema, and chronic pain are common complications of hernia repair. Laparoscopic techniques have ushered in a new era in hernia repair and offer less early postoperative pain, less need for analgesics, lower rates of wound infection, better cosmetic results, and faster return to work. ${ }^{1-3}$ The National Institute of Clinical Excellence reported a meta-analysis of more than 40 controlled trials and reported that laparoscopic repair is superior to open surgery in terms of pain and recovery in $2001 .{ }^{4}$ However, its operative cost is higher than open techniques despite the overall cost favoring laparoscopic approaches in terms of postoperative outcomes. ${ }^{5}$ Total extraperitoneal (TEP) is the most frequently preferred method among laparoscopic hernia repair techniques. Unlike other techniques, TEP does not require the intraperitoneal cavity to be entered meaning that intra-abdominal complications such as organ injury and postoperative ileus can be 
avoided. TEP repairs under regional anesthesia have been reported, ${ }^{6-8}$ but there are few studies comparing general and regional anesthesia.

Spinal or epidural anesthesia in laparoscopic repair has been used for years. ${ }^{9,10}$ We compared the advantages and disadvantages of open repair and laparoscopic TEP repairs under general anesthesia (GA) and spinal anesthesia (SA) in this clinical trial.

\section{Methods}

Patients $(n=440)$ who underwent surgery for unilateral inguinal hernia between January 2013 and June 2015 in a governmental hospital were analyzed retrospectively. The same surgeon and the same anesthesiologist performed the procedures. The most common complaints were swelling and pain. Patients were diagnosed via physical examination and ultrasonography. The inclusion criteria were age between 18 and 70 years, elective repair, and unilateral hernia. The exclusion criteria were patients on anticoagulation treatment; psychiatric comorbidities; recurrent hernias, strangulated, incarcerated, or bilateral hernia; and the presence of spinal deformity, coagulopathy, and drug allergy history. There were four groups: Group 1 was TEP under GA (TEP-GA) $(n=111)$; Group 2 was open mesh repair $(\mathrm{OM})$ under SA $(n=116)$ (OM-SA); Group 3 was open mesh repair under GA ( $n=117)$ (OM-GA); Group 4 was TEP under SA (n=96) (TEP-SA). The patients were given surgical and anesthetic options and asked to choose. A preoperative single dose of first-generation cephalosporin prophylaxis was used for all patients. We compared the following: age, body mass index (BMI), duration of surgery, hospital stay, hypotension, vomiting, seroma and scrotal edema, postoperative pain perception with Visual Analog Scale (VAS) in the 1st, 4th, 12th, and 24th hours (VAS 1, VAS 4, VAS 12 and VAS 24, respectively), recurrence, postoperative pain and chronic pain, urinary retention (inability to urinate spontaneously during the early postoperative period requiring application of heat or urinary catheterization), headache, and patient satisfaction via a Likert scale (between 0 and 5 where 0 was not satisfied at all and 5 was very satisfied). Seroma and scrotal edema were evaluated with ultrasonography. All anesthesia and operations were done by the same anesthesiologist and surgeon. All patients were followed up to 12th month of operation either by phone or at outpatient clinics on the 10 th day, 1st, 3rd, 9th, and 12th months. They were advised to report to outpatient clinics if any symptoms emerged. They were questioned about chronic groin pain on the $3 \mathrm{rd}$ and 9th months and about their satisfaction at the end of the 3rd postoperative month.

\section{Statistical analysis}

SPSS 15.0 (SPSS Inc., Chicago, IL, USA) for Windows was used for statistical analysis. Descriptive statistics were given as number and percent for categorical variables, and mean and SD for numerical variables. Kruskal-Wallis test was used in the comparison of more than two independent groups, as numerical variables did not provide normal distribution condition. Subgroup analyses were done with Mann-Whitney $U$ test. As the difference of numerical variables in more than two dependent groups did not provide normal distribution situation, Friedman analysis was used. Wilcoxon analysis was used for subgroup comparison; subgroup analyses of dependent independent groups were interpreted by using Bonferroni correction. Chi-squared test was used in comparing the ratios within each independent group. When Pearson chi-square conditions were not provided, Monte Carlo simulation was used. $\alpha$ significance level was accepted as $P<0.05$.

\section{Ethics statement}

As this was a retrospective study, ethical approval was verbally requested from the Haydarpasa Numune Ethical Committee who advised that ethical approval was not needed. Written informed consent, however, this study was conducted in respect with human rights and written informed consent was obtained from each of the patients.

\section{Results}

The mean ages were $39.9 \pm 16.2,38.1 \pm 16.8,39.1 \pm 16.5$, and $31.8 \pm 10.9$ years for Groups $1-4$, respectively, with significant differences among the groups $(P=0.005)$. The mean age in TEP-SA was younger than TEP-GA and OM-GA $(P<0.001$ and $P=0.004$, respectively) (Table 1 ).

The mean BMIs were 25.7 $\pm 3.1,24.9 \pm 3.2,24.3 \pm 3.2$, and $23.8 \pm 3.2$ for Groups 1-4, respectively, with significant difference between the groups $(P=0.001)$. The mean BMI in TEP-GA was significantly higher than OM-GA and TEP-SA $(P=0.003$ and $P<0.001)$ (Table 1$)$.

There was no statistically significant difference between hernia neck diameter averages $(P=0.892)$.

The mean duration of operation periods were 50.4 \pm 7.3 , $38.1 \pm 5.9,38.7 \pm 5.9$, and 55.0 \pm 8.3 minutes for Groups 1-4, respectively, with significant difference between the groups $(P<0.001)$. The duration of operation was the longest in 
Table I Patient demographics, operation, hospital durations, and hernia neck diameters

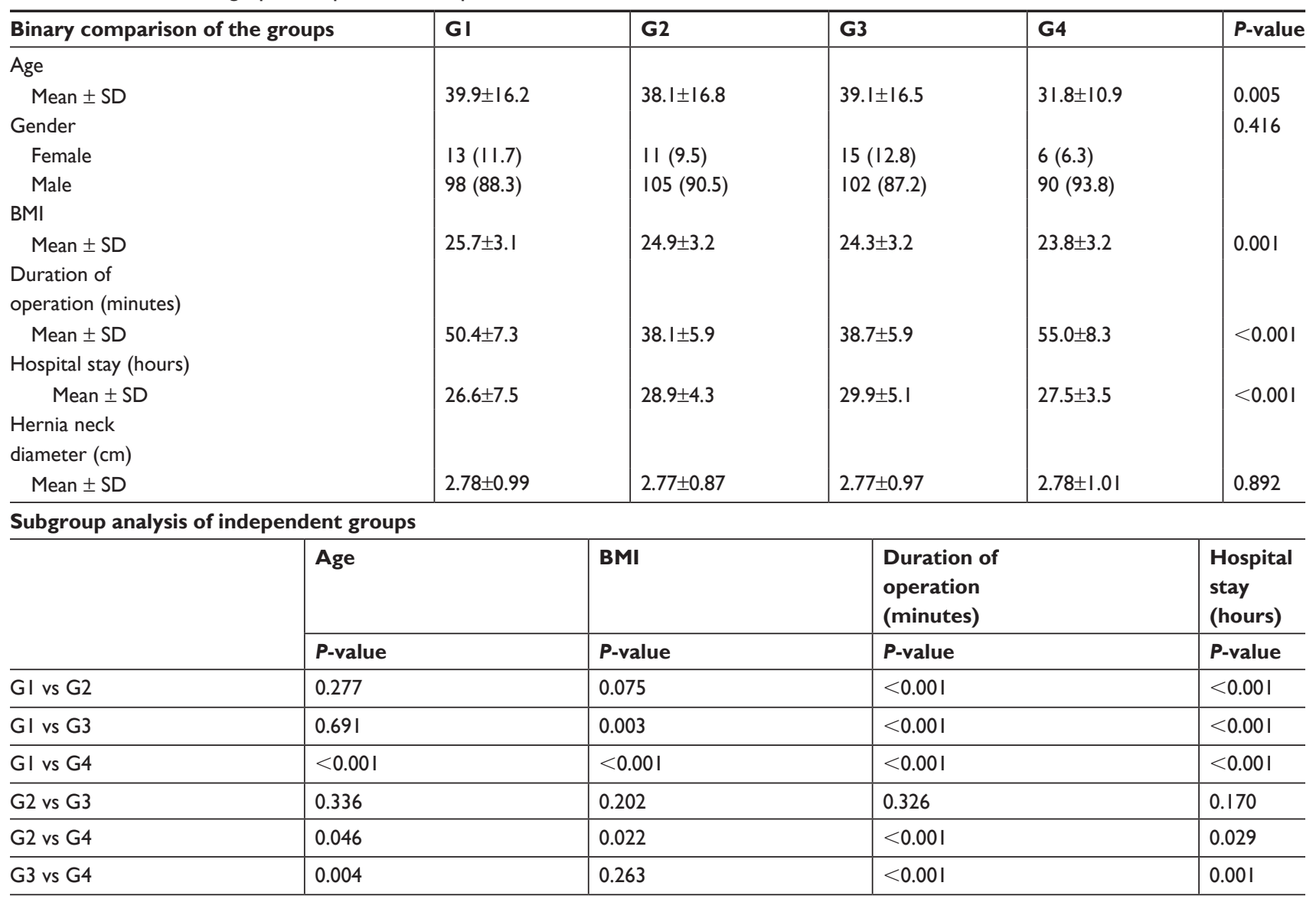

Notes: G1: TEP-GA; G2: OM-SA; G3: OM-GA; G4: TEP-SA.

Abbreviations: GA, general anesthesia; OM, open mesh repair; SA, spinal anesthesia; TEP, total extraperitoneal.

TEP-SA followed by TEP-GA and OM-GA $(P<0.001$, for all) (Table 1).

The mean hospital stay periods were $26.6 \pm 7.5,28.9 \pm 4.3$, $29.9 \pm 5.1$, and $27.5 \pm 3.5$ hours for Groups $1-4$, respectively, with significant differences for all groups $(P<0.001)$. It was shortest in TEP-GA followed by TEP-SA, OM-SA and OM-GA $(P<0.001 ; P<0.001 ; P<0.001 ; P=0.001$, respectively).

Hypotension, vomiting, seroma, scrotal edema, and wound infection incidence did not differ significantly between the groups (Table 2). The wound infection was superficial: one at the umbilical port, which responded to antibiotic treatment. These complications did not necessitate conversion to GA or open surgery. There was no statistically significant difference in preoperative VAS averages between the groups $(P=0.846)$. The postoperative mean VAS 1 values were $5.11 \pm 0.85$, $0.32 \pm 0.47,8.61 \pm 0.49$, and $0.10 \pm 0.31$. VAS 4 values were $3.53 \pm 0.70,5.67 \pm 0.60,6.00 \pm 0.69$, and $2.18 \pm 0.63$. VAS 12 values were $1.78 \pm 0.72,4.70 \pm 0.66,5.13 \pm 0.86$, and $1.40 \pm 0.51$. VAS 24 ( 24 hours post-op) values were $0.75 \pm 0.58$,
$4.84 \pm 1.03,4.21 \pm 0.68$, and $0.89 \pm 0.48$, respectively. VAS 1,4 , 12 , and 24 had significant difference when compared between the groups $(P<0.01)$ (Table 3$)$.

The postoperative mean VAS 1 was lowest in TEP-SA followed by OM-SA and TEP-GA and OM-GA. The postoperative mean VAS 4 and VAS 12 values were lowest in TEP-SA. This was lower in TEP-GA than OM-SA and OM-GA. There was a significant difference between the postoperative mean VAS 24 values of TEP-GA and TEP-SA. TEP-GA and TEP-SA were lower than OM-SA and OM-GA. The OM-GA was lower than OM-SA (postoperative VAS 24 for TEP-GA vs TEP-SA $P=0.049$; for all other comparisons, $P<0.001$ ).

The change in VAS scores within each group was also significant $(P<0.001$ for all). VAS 4 values were significantly decreased in TEP-GA and OM-GA and increased in OM-SA and TEP-SA vs VAS 1. There was a significant decrease in VAS 12 in all groups. Postoperative VAS 24 values were significantly increased in OM-SA compared to VAS 12 but significantly decreased in all other groups $(P<0.001$ for 
Table 2 Post operative complications and outcome

\begin{tabular}{|c|c|c|c|c|c|c|c|c|c|}
\hline \multirow{2}{*}{$\begin{array}{l}\text { Complications and } \\
\text { outcome }\end{array}$} & \multicolumn{2}{|l|}{ GI } & \multicolumn{2}{|l|}{ G2 } & \multicolumn{2}{|l|}{ G3 } & \multicolumn{2}{|l|}{ G4 } & \multirow[t]{2}{*}{$P$-value } \\
\hline & $\mathbf{n}$ & $\%$ & $\mathbf{n}$ & $\%$ & $\mathbf{n}$ & $\%$ & $\mathbf{n}$ & $\%$ & \\
\hline Hypotension & 3 & 2.7 & 4 & 3.4 & 4 & 3.4 & 6 & 6.3 & 0.637 \\
\hline Vomiting & 4 & 3.6 & 3 & 2.6 & 6 & 5.1 & 7 & 7.3 & 0.390 \\
\hline Recurrence & 3 & 2.7 & 8 & 6.89 & 7 & 5.98 & 3 & 3.1 & 0.112 \\
\hline Seroma & 6 & 5.4 & 9 & 7.8 & 11 & 9.4 & 9 & 9.4 & 0.662 \\
\hline Scrotal edema & 5 & 4.5 & 7 & 6.0 & 9 & 7.7 & 11 & 11.5 & 0.256 \\
\hline Wound infection & 4 & 3.6 & 8 & 6.9 & 10 & 8.5 & 7 & 7.3 & 0.488 \\
\hline \multicolumn{10}{|l|}{ Likert scale } \\
\hline Mean \pm SD & $4.32 \pm 0.74$ & & $2.38 \pm 0.55$ & & $2.43 \pm 0.56$ & & $4.43 \pm 0.64$ & & $<0.001$ \\
\hline Pain at 3rd month & 5 & 4.5 & 18 & 15.5 & II & 9.4 & 7 & 7.3 & 0.032 \\
\hline Pain at 9th month & 3 & 2.7 & 7 & 6.0 & 8 & 6.8 & 2 & 2.1 & 0.239 \\
\hline Urinary retention & I & 0.9 & 14 & 12.1 & I & 0.9 & 7 & 7.3 & $<0.001$ \\
\hline Headache & 1 & 0.9 & 12 & 10.3 & 2 & 1.7 & 7 & 7.3 & 0.002 \\
\hline \multicolumn{10}{|c|}{ Analysis of subgroup analysis of independent groups } \\
\hline \multirow[t]{2}{*}{$\begin{array}{l}\text { Binary comparison } \\
\text { of the groups }\end{array}$} & \multicolumn{2}{|c|}{ Recurrence } & \multicolumn{2}{|c|}{\begin{tabular}{|l} 
Pain at \\
3rd month
\end{tabular}} & \multicolumn{2}{|l|}{$\begin{array}{l}\text { Urinary } \\
\text { retention }\end{array}$} & \multicolumn{2}{|l|}{ Headache } & $\begin{array}{l}\text { Likert } \\
\text { scale }\end{array}$ \\
\hline & \multicolumn{2}{|l|}{$P$-value } & \multicolumn{2}{|l|}{$P$-value } & \multicolumn{2}{|l|}{$P$-value } & \multicolumn{2}{|l|}{$P$-value } & $P$-value \\
\hline GI vs $\mathrm{G} 2$ & \multicolumn{2}{|l|}{0.856} & \multicolumn{2}{|l|}{0.006} & \multicolumn{2}{|l|}{0.001} & \multicolumn{2}{|l|}{0.002} & $<0.001$ \\
\hline GI vs G3 & \multicolumn{2}{|l|}{0.652} & \multicolumn{2}{|l|}{0.148} & \multicolumn{2}{|l|}{1.000} & \multicolumn{2}{|l|}{1.000} & $<0.001$ \\
\hline GI vs G4 & \multicolumn{2}{|l|}{1.000} & \multicolumn{2}{|l|}{0.392} & \multicolumn{2}{|l|}{0.026} & \multicolumn{2}{|l|}{0.026} & 0.347 \\
\hline $\mathrm{G} 2$ vs $\mathrm{G} 3$ & \multicolumn{2}{|l|}{0.809} & \multicolumn{2}{|l|}{0.157} & \multicolumn{2}{|l|}{$<0.00 \mathrm{I}$} & \multicolumn{2}{|l|}{0.006} & 0.486 \\
\hline $\mathrm{G} 2$ vs $\mathrm{G} 4$ & 0.728 & & 0.065 & & 0.246 & & 0.439 & & $<0.001$ \\
\hline G3 vs G4 & 0.967 & & 0.582 & & 0.024 & & 0.082 & & $<0.001$ \\
\hline
\end{tabular}

Notes: GI: TEP-GA; G2: OM-SA; G3: OM-GA; G4: TEP-SA.

Abbreviations: GA, general anesthesia; OM, open mesh repair; SA, spinal anesthesia; TEP, total extraperitoneal.

all subgroups). The pain scores (VAS) were significantly higher in open surgery groups, and it was also significantly different upon comparing open groups between each other. The VAS 24 also showed significant differences between TEP groups (Table 3 ).
The recurrence from groups $1-4$ rates were $3(2.7 \%)$, $8(6.89 \%), 7(5.98 \%)$, and $3(3.1 \%)$, respectively, and there were no significant differences between the groups ( $P=0.112$ ). Recurrence rates were higher in both the open repair groups and the TEP (Table 2).

Table 3 VAS scores as a function of time

\begin{tabular}{|c|c|c|c|c|c|c|}
\hline & \multirow[t]{2}{*}{ Hours } & Group G I & \multirow{2}{*}{$\begin{array}{l}\text { G2 } \\
\text { Mean } \pm \text { SD }\end{array}$} & \multirow{2}{*}{$\begin{array}{l}\text { G3 } \\
\text { Mean } \pm \text { SD }\end{array}$} & G4 & \multirow[t]{2}{*}{$P$-value } \\
\hline & & Mean \pm SD & & & Mean \pm SD & \\
\hline VAS & $\begin{array}{l}\text { Preop } \\
\text { Postop I } \\
\text { Postop } 4 \\
\text { Postop I2 } \\
\text { Postop } 24 \\
\text { P-value }\end{array}$ & $\begin{array}{l}0.15 \pm 0.40 \\
5.11 \pm 0.85 \\
3.53 \pm 0.70 \\
1.78 \pm 0.72 \\
0.75 \pm 0.58 \\
<0.001\end{array}$ & $\begin{array}{l}0.20 \pm 0.46 \\
0.32 \pm 0.47 \\
5.67 \pm 0.60 \\
4.70 \pm 0.66 \\
4.84 \pm 1.03 \\
<0.001\end{array}$ & $\begin{array}{l}0.16 \pm 0.39 \\
8.61 \pm 0.49 \\
6.00 \pm 0.69 \\
5.13 \pm 0.86 \\
4.21 \pm 0.68 \\
<0.001\end{array}$ & $\begin{array}{l}0.18 \pm 0.44 \\
0.10 \pm 0.31 \\
2.18 \pm 0.63 \\
1.40 \pm 0.51 \\
0.89 \pm 0.48 \\
<0.001\end{array}$ & $\begin{array}{l}0.846 \\
<0.00 \text { I } \\
<0.00 \text { I } \\
<0.00 \text { I } \\
<0.00 \text { I }\end{array}$ \\
\hline \multirow{2}{*}{\multicolumn{2}{|c|}{$\begin{array}{l}\text { Binary comparison of the } \\
\text { groups }\end{array}$}} & $\begin{array}{l}\text { Postop } \\
\text { I VAS }\end{array}$ & \multicolumn{2}{|l|}{$\begin{array}{l}\text { Postop } \\
4 \text { VAS }\end{array}$} & $\begin{array}{l}\text { Postop } \\
\text { I } 2 \text { VAS }\end{array}$ & $\begin{array}{l}\text { Postop } \\
24 \text { VAS }\end{array}$ \\
\hline & & $P$-value & \multicolumn{2}{|l|}{$P$-value } & $P$-value & $P$-value \\
\hline \multicolumn{2}{|c|}{ GI vs $G 2$} & $<0.001$ & \multicolumn{2}{|l|}{$<0.001$} & $<0.001$ & $<0.001$ \\
\hline \multicolumn{2}{|c|}{ GI vs G3 } & $<0.001$ & \multicolumn{2}{|l|}{$<0.001$} & $<0.00$ I & $<0.001$ \\
\hline \multicolumn{2}{|c|}{ GI vs $G 4$} & $<0.001$ & \multicolumn{2}{|l|}{$<0.001$} & $<0.001$ & 0.049 \\
\hline $\mathrm{G} 2$ vs & & $<0.001$ & $<0.001$ & & $<0.001$ & $<0.001$ \\
\hline $\mathrm{G} 2$ vs & & $<0.001$ & $<0.001$ & & $<0.001$ & $<0.001$ \\
\hline G3 vs & & $<0.001$ & $<0.001$ & & $<0.001$ & $<0.001$ \\
\hline
\end{tabular}

Notes: GI: TEP-GA; G2: OM-SA; G3: OM-GA; G4: TEP-SA.

Abbreviations: GA, general anesthesia; OM, open mesh repair; SA, spinal anesthesia; TEP, total extraperitoneal; VAS, Visual analog scale. 
Chronic pain at the 3rd month was seen in $5(4.5 \%)$, $18(15.5 \%), 11(9.45 \%)$, and $7(7.3 \%)$ patients with significant differences among groups $1-4(P=0.032)$. Chronic pain at the 3rd postoperative month had no significant difference between TEP and open groups except TEP-GA and OM-SA where it was significant. It was higher in both open repair groups and highest in OM-SA (Table 2).

Urinary retention incidences in groups $1-4$ were $1(0.9 \%)$, $14(12.1 \%), 1(0.9 \%)$, and $7(7.3 \%)$, respectively. It was higher in OM-SA and TEP-SA than TEP-GA and OM-GA ( $P=0.001, P=0.026, P<0.001$, and $P=0.024$ ) (Table 2).

Headache incidences in groups $1-4$ were $1(0.9 \%), 12$ $(10.3 \%), 2(1.7 \%)$, and $7(7.3 \%)$, respectively. Its incidence was significantly higher in OM-SA than TEP-GA $(P=0.006)$. Headache incidence was higher in OM-SA vs TEP-GA and OM-GA and in TEP-SA vs TEP-GA ( $P=0.002, P=0.026$, and $P=0.006$, respectively). Headache was higher in spinal groups. It was higher in the OM-SA group relative to the TEP-SA group (Table 2).

The mean Likert scores for groups 1-4 were $4.32 \pm 0.74$, $2.38 \pm 0.55,2.43 \pm 0.56$, and $4.43 \pm 0.64$, respectively. This score was higher in both TEP groups, and these values had significant differences vs the open repair groups $(P<0.001$ for all) (Table 2).

\section{Discussion}

Inguinal hernia repair is one of the most common surgical operations with 700,000 cases per year in the USA. ${ }^{11}$ McVay, Bassini, posterior wall-darn, anterior, and posterior repair with synthetic grafts have all been used in inguinal hernia repair. European surgical guidelines propose that the Lichtenstein technique decreases recurrence rate; thus, it is accepted as the gold standard., ${ }^{3,12}$ In recent years, endoscopic repair techniques have been preferred for the repair of inguinal hernias. The TEP technique is advantageous vs other techniques. Less postoperative and chronic pain and better cosmetic results are the advantage of TEP. In contrast to other endoscopic repairs, TEP has no intraperitoneal access and thus has no risk of intraperitoneal complication developments (intestinal or main vessel injury, postoperative obstruction, etc.). Its recurrence rate was reported to be $1 \%-4 \%$. Its main disadvantage is its difficulty depending on the experience and learning curve. ${ }^{1,3}$ The surgical results depend on the experience of the surgical team in the specific technique.

A recent study comparing laparoscopic vs open surgery found that laparoscopic repair was superior to open one in terms of surgical outcome and complications., 3 Another meta-analysis found that the frequency of complications was 1.76 times higher in open repair than laparoscopic repair. ${ }^{13}$
Our findings did not correlate to their results in terms of complications.

Laparoscopic hernia repair under SA has been popular in recent years. Lap trans abdominal pre-peritoneal under SA is not widely accepted because of muscular relaxation problems. In totally extra peritoneal, anatomical delineation of the surgical space is satisfactory in recent studies, ${ }^{14-16}$ but few studies are available. Thus, it is not yet in the guidelines.

A longer duration of operation is a problem in laparoscopic hernia repair vs open one. Studies have reported variable results in terms of the statistical significance of this duration difference. ${ }^{3,9,14-19}$

In our study, there were no significant differences in hypotension, vomiting, seroma and scrotal edema formation, and wound infection incidence between the groups. However, the operation duration, hospital stay period, headache, urinary retention, postoperative VAS scores, chronic pain, and patient satisfaction did have significant differences. ${ }^{2,3}$ Seroma and scrotal edema recovered by itself within 3 months.

Our results showed that both laparoscopic hernia repair groups had longer operation durations than open surgery $(P<0.001)$. This is similar to a meta-analysis of seven studies comparing open preperitoneal and laparoscopic repair, which reported that laparoscopic repair methods took longer to perform. ${ }^{18}$ However, our laparoscopic repair durations were shorter than those reported in the literature. ${ }^{20}$ The duration was longer in the TEP-SA group than in TEP-GA $(P<0.001)$. This might be because of the prolonged anesthesia used in SA. There were no differences in term of duration of surgery between the Lichtenstein repair groups $(P=0.326)$ (Table 1$)$.

The hospital stay period is an important parameter to study the effectiveness of the technique. This period varies between 1 and 4 days for laparoscopic hernia repair in the literature..$^{3,9,14,16,17,21,22}$ The 1.5 days of hospitalization is acceptable, and all groups had a significant difference in terms of their hospital stay period $(P<0.01)$. Open groups did not have a significant difference $(P=0.170)$. Both TEP groups had a shorter hospital stay. This might be because of less early postoperative pain due to fewer incisions; thus, it is more comfortable for the early postoperative period in TEP.

Postoperative pain perception is important and was evaluated by the VAS. The VAS scores were significantly lower in the SA groups on the first hour. The VAS decreased significantly in the TEP-GA and OM-GA groups from VAS 1 to VAS 24. In contrast, there was a peak increase in VAS 4 and then a significant decrease in TEP-SA and OM-SA groups, but these peak values were approximately equal to TEP-GA and OM-GA values of VAS 4, respectively (Figure 1). These VAS scores showed a significant 


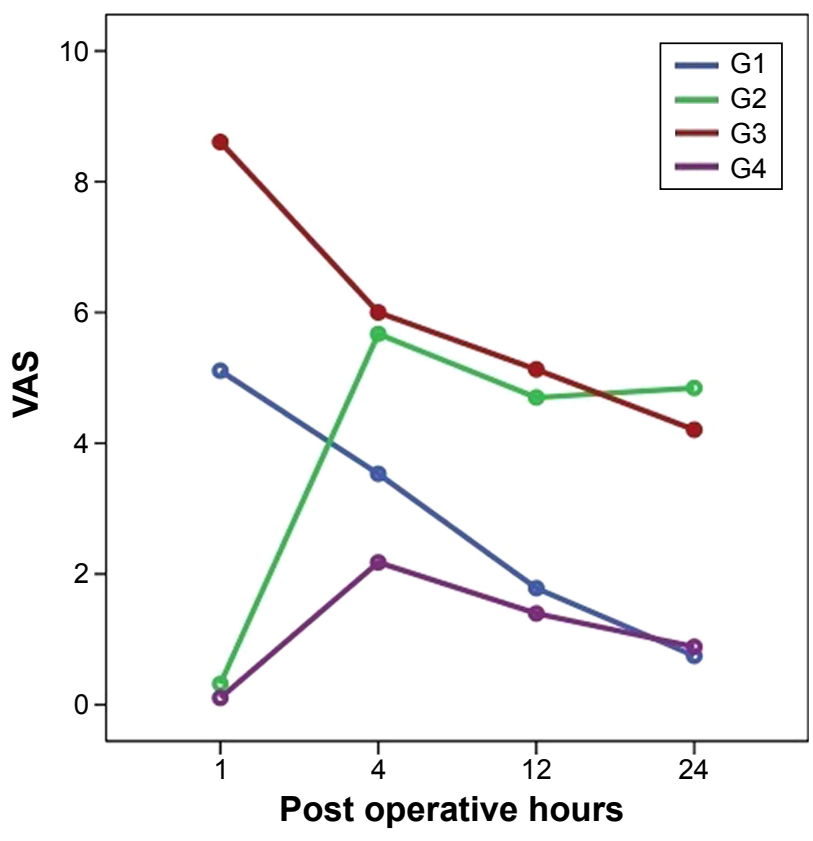

Figure I VAS score graphics.

difference within and between the groups (Table 2). The TEP was superior to open repair in terms of postoperative pain. The SA interestingly showed increased pain on VAS 4 followed by a decrease. In contrast, the GA groups had a continuous decrease within 24 hours (Figure 1). The operation technique was more important than anesthesia in terms of postoperative pain perception. Our results correlated with those of Ciftci et $\mathrm{al}^{21}$ who reported significantly lower VAS scores in the TEP group than the open technique within the first postoperative day.

Recurrence rates showed no significant difference among groups $(P=0.112)$ (Table 2$)$. The recurrences in the TEP groups were slightly higher than those reported in the literature. , $^{3,14-16,22}$

Urinary retention is common in SA. ${ }^{3,15,16}$ Urinary retention was significantly higher in the SA groups. It was higher in the OM-SA group than the TEP-SA group, but not statistically significant (Table 2). The GA differences were not significant. SA is a single risk factor for urinary retention. This is in contrast to Donmez et $\mathrm{al}^{14}$ who found no urinary retention in SA but two in the GA group. Symeonidis et $\mathrm{al}^{23}$ reported that TAPP under SA had a higher incidence of urinary retention $(36 \%)$ followed by open repair under SA $(32 \%)$ vs open repair under SA and GA (16\% and 12\%, respectively). These results suggest that both laparoscopy and SA had a combined increasing effect on urinary retention. ${ }^{22}$

We found that chronic pain on the 3rd month was higher in both open repair groups. There was a significant difference among groups $(P=0.032)$ (Table 2). Subgroup analysis revealed a significant difference between TEP-GA and OM-SA $(P=0.006)$; other subgroup analyses showed no significant differences (Table 2).

At the end of the 9 th month, chronic groin pain rates were $2.7 \%$ and $2.1 \%$ in the TEP-GA and TEP-SA groups, respectively; these were $6.0 \%$ and $6.8 \%$ in the OM-SA and OM-GA groups, respectively. There was no significant difference between the groups, statistically, at 9 months (Table 2).

Mommers et $\mathrm{al}^{24}$ reported chronic pain in 22 patients (19\%) after the 6th week and in 17 patients (14\%) after 1 year following TEP. Sajid et $\mathrm{al}^{18}$ concluded that open repair had a shorter duration of surgery and comparable results in terms of chronic pain, recurrence, and postoperative pain vs laparoscopic approaches; they suggested the routine use of open repair. However, our results show that rates of laparoscopic hernia were lower, but there were no significant differences between laparoscopic and open groups except TEP-GA and OM-SA. Correlation between chronic pain and repair and anesthesia techniques could not be assessed in the light of these findings. Singh et al reported that preoperative pain, young age, open repair, and 1st week postoperative pain were independent risk factors of chronic pain. ${ }^{25}$

Headache is a common side effect of SA. Our results also showed a significant difference between GA and SA groups. Headache incidence was higher in SA groups than in GA groups and more frequent in the OM-SA group than the TEP-SA. Headache seems to be specific for SA. The headache in our groups responded to fluid and caffeine-rich beverage intake within 2 postoperative days. Sinha et $\mathrm{al}^{9}$ reported headache in 25 patients $(5.21 \%)$ with a mean duration of 2.6 days for TEP-SA. They managed it by making the patients lie down and also increase fluid and salt intake. 9 On the contrary, Donmez et $\mathrm{al}^{14}$ reported headache in $2(8 \%)$ for GA but not in the SA group.

Patient satisfaction is important in hernia repair. All groups showed a significant difference $(P<0.001)$, and our findings were in favor of the TEP groups in which satisfaction rates were higher than open repair ones (Table 2). It seems that satisfaction depends on surgical technique more than anesthesia. Better satisfaction scores were found for TEP-SA in the literature as well., ${ }^{9,14,15}$ TEP was reported to have higher satisfaction scores vs TAPP. ${ }^{1}$

\section{Conclusion}

Laparoscopic TEP hernia repair is a safe and effective method that offers shorter hospital stays, less recurrence, less postoperative pain, higher patient satisfaction, and similar postoperative complication rates. SA suffers from a higher incidence of headache and urinary retention vs GA. SA can 
be safely performed in both open and laparoscopic inguinal hernia repair.

\section{Data sharing statement}

Raw material and data are available upon request.

\section{Acknowledgment}

This study was presented as oral presentation in 39th Annual International European Hernia Congress (EHS 2017) in Vienna between 24th and 27th of May, 2017.

\section{Disclosure}

The authors report no conflicts of interest in this work.

\section{References}

1. Krishna A, Misra MC, Bansal VK, Kumar S, Rajeshwari S, Chabra A. Laparoscopic inguinal hernia repair: transabdominal preperitoneal (TAPP) versus totally extraperitoneal (TEP) approach: a prospective randomized controlled trial. Surg Endosc. 2012;26(3):639-649.

2. Neumayer L, Giobbie-Hurder A, Jonasson O, et al. Open mesh versus laparoscopic mesh repair of inguinal hernia. $N$ Engl J Med. 2004; 350(18):1819-1827.

3. Simons MP, Smietanski M, Bonjer HJ, Bittner R, Miserez M, Aufenacker TJ, HerniaSurge group. International guidelines for groin hernia management. Hernia. 2018;22:1-165.

4. National Institute for Clinical Excellence. Guidance on the Use of Laparoscopic Surgery for Inguinal Hernia, Technological Appraisal Guidance No. 18. London: NICE; 2001.

5. Tadaki C, Lomelin D, Simorov A, et al. Perioperative outcomes and costs of laparoscopic versus open inguinal hernia repair. Hernia. 2016;20(3):399-404.

6. Pendurthi TK, Demaria EJ, Kellum JM. Laparoscopic bilateral inguinal hernia repair under local anesthesia. Surg Endosc. 1995;9(2):197-199.

7. Molinelli BM, Tagliavia A, Bernstein D. Total extraperitoneal preperitoneal laparoscopic hernia repair using spinal anesthesia. JSLS 2006;10(3):341-344.

8. Lau H, Wong C, Chu K, Patil NG. Endoscopic totally extraperitoneal inguinal hernioplasty under spinal anesthesia. J Laparoendosc Adv Surg Tech A. 2005;15(2):121-124.

9. Sinha R, Gurwara AK, Gupta SC. Laparoscopic total extraperitoneal inguinal hernia repair under spinal anesthesia: a study of 480 patients. J Laparoendosc Adv Surg Tech A. 2008;18(5):673-677.

10. Lal P, Philips P, Saxena KN, Kajla RK, Chander J, Ramteke VK. Laparoscopic total extraperitoneal (TEP) inguinal hernia repair under epidural anesthesia: a detailed evaluation. Surg Endosc. 2007;21(4):595-601.

11. Belyansky I, Tsirline VB, Klima DA, Walters AL, Lincourt AE, Heniford TB. Prospective, comparative study of postoperative quality of life in TEP, TAPP, and modified Lichtenstein repairs. Ann Surg. 2011;254(5):709-715.
12. Bringman S, Ramel S, Heikkinen TJ, Englund T, Westman B, Anderberg B. Tension-free inguinal hernia repair: TEP versus mesh-plug versus Lichtenstein: a prospective randomized controlled trial. Ann Surg. 2003;237(1):142-147.

13. Memon MA, Cooper NJ, Memon B, Memon MI, Abrams KR. Metaanalysis of randomized clinical trials comparing open and laparoscopic inguinal hernia repair. Br J Surg. 2003;90(12):1479-1492.

14. Donmez T, Erdem VM, Sunamak O, Erdem DA, Avaroglu HI. Laparoscopic total extraperitoneal repair under spinal anesthesia versus general anesthesia: a randomized prospective study. Ther Clin Risk Manag. 2016;12:1599-1608.

15. Dhankhar DS, Sharma N, Mishra T, Kaur N, Singh S, Gupta S. Totally extraperitoneal repair under general anesthesia versus Lichtenstein repair under local anesthesia for unilateral inguinal hernia: a prospective randomized controlled trial. Surg Endosc. 2014;28(3):996-1002.

16. Shaikh AG, Soomro MI, Shaikh MS, Memon AA. Outcome of totally extra-peritoneal laparoscopic hernioplasty at a tertiary care hospital Larkana. J Pak Med Assoc. 2013;63(7):850-853.

17. Shakya VC, Sood S, Bhattarai BK, Agrawal CS, Adhikary S. Laparoscopic inguinal hernia repair: a prospective evaluation at Eastern Nepal. Pan African Medical Journal. 2014;17:241.

18. Sajid MS, Caswell J, Singh KK. Laparoscopic versus open preperitoneal mesh repair of inguinal hernia: An integrated systemic review and meta-analysis of laparoscopic versus open preperitoneal mesh repair of inguinal hernia: An integrated systematic review and metanalysis of published randomized controlled trials. Indian J Surg. 2015;77(Suppl 3): $1258-1269$.

19. Ismail M, Garg P. Laparoscopic inguinal total extraperitoneal hernia repair under spinal anesthesia without mesh fixation in 1,220 hernia repairs. Hernia. 2009;13(2):115-119.

20. Reiner MA, Bresnahan ER. Laparoscopic Total Extraperitoneal Hernia Repair Outcomes. JSLS. 2016;20(3):e2016.00043.

21. Ciftci F, Abdulrahman I, Ibrahimoglu F, Kilic G. Early-stage quantitative analysis of the effect of laparoscopic versus conventional inguinal hernia repair on physical activity. Chirurgia. 2015;110(5):451-456.

22. Jakhmola CK, Kumar A. Laparoscopic inguinal hernia repair in the Armed Forces: A 5-year single centre study. Med J Armed Forces India. 2015;71(4):317-323.

23. Symeonidis D, Baloyiannis I, Koukoulis G, et al. Prospective nonrandomized comparison of open versus laparoscopic transabdominal preperitoneal (TAPP) inguinal hernia repair under different anesthetic methods. Surg Today. 2014;44(5):906-913.

24. Mommers EHH, Hünen DRM, van Hout J, et al. Patient-reported outcomes (PROs) after total extraperitoneal hernia repair (TEP). Hernia. 2017;21(1):45-50.

25. Singh AN, Bansal VK, Misra MC, et al. Testicular functions, chronic groin pain, and quality of life after laparoscopic and open mesh repair of inguinal hernia: a prospective randomized controlled trial. Surg Endosc. 2012;26(5):1304-1317.

\section{Dovepress}

\section{Publish your work in this journal}

Therapeutics and Clinical Risk Management is an international, peerreviewed journal of clinical therapeutics and risk management, focusing on concise rapid reporting of clinical studies in all therapeutic areas, outcomes, safety, and programs for the effective, safe, and sustained use of medicines. This journal is indexed on PubMed Central, CAS,
EMBase, Scopus and the Elsevier Bibliographic databases. The manuscript management system is completely online and includes a very quick and fair peer-review system, which is all easy to use. Visit http://www.dovepress.com/testimonials.php to read real quotes from published authors. 